\title{
Characterization of aluminium metal matrix composite fabricated by gas injection bottom pouring vacuum multi-stir casting process
}

\author{
M. Kataria ${ }^{1}$, S. K. Mangal ${ }^{2}$ \\ Department of Mechanical Engineering, Punjab Engineering College, Chandigarh 160012, India
}

Received 4 April 2018, received in revised form 3 July 2018, accepted 18 July 2018

\begin{abstract}
In the present work, a newly developed gas injection bottom pouring vacuum stir casting technique has been envisaged for the fabrication of Aluminium MMCs which is a fully automated and one of its kind. Aluminium 6063-T6 alloy is used as the matrix, and the aluminium oxide $\left(\mathrm{Al}_{2} \mathrm{O}_{3}\right)$ particles are taken as reinforcement. Different experiments have been performed on the fabricated MMCs to ascertain its mechanical and morphological properties. The presence of various elements and grain morphology of the fabricated MMCs are confirmed by Energy Dispersive Spectroscopy (EDS), Scanning Electron Microscope (SEM) and mapping. The experimental results revealed that the hardness of $\mathrm{Al} / \mathrm{Al}_{2} \mathrm{O}_{3} \mathrm{MMC}$ had increased by 1.71 times and maximum tensile strength had increased by 1.27 times in comparison to the monolithic aluminium alloy. The results establish that the proposed methodology of MMC fabrication can be effectively utilized for fabrication of homogeneously reinforced MMCs for various engineering and industrial applications.
\end{abstract}

$\mathrm{K}$ e y word s: metal matrix composite, aluminium alloy, $\mathrm{Al}_{2} \mathrm{O}_{3}$, bottom pouring stir casting, multi-step stirring, characterization

\section{Introduction}

Composite materials are those materials which consist of two or more physically and chemically dissimilar phased materials. The continuous phase of this material is termed as matrix while the discrete phase is termed as reinforcement. When the matrix in the composite material is metal, then it is termed a Metal Matrix Composite (MMC). In MMCs, the reinforcement generally is in the form of particles, whiskers and short or continuous fibres [1]. These MMCs offer far superior characteristics, e.g. higher specific strength, better structural efficiency, reliability, wear resistance and control over its physical properties such as coefficient of thermal expansion and density which in turn provides better technical performance when compared with the monolithic materials [2-8].

In recent times aluminium and its alloy based MMCs have gained a lot of popularity and are being utilized in all the emerging fields of engineering and technology, e.g. aerospace, defence, automotive and thermal management areas, in sports, recreation, etc. owing to its lower creep rate, better fatigue resistance and better specific strength as compared to monolithic materials [9]. The viscoelastic response of these aluminium MMCs shows the most stable behaviour and a rapid decrease in its stiffness is seen only at very high temperature. Aluminium MMCs also show higher stiffness and higher mechanical damping/internal friction when compared to pure aluminium [10].

The MMCs are usually processed with liquid metal routes such as stir casting and infiltration. Powder metallurgy route is also sometimes used which incorporates sintering \& extrusion. This route has the potential for specifically weight-critical engineering applications [11]. Nowadays, 3D printing is under extensive exploration and is being used to fabricate aluminium MMCs. The experimental results have proved the efficacy of laser 3D printing technology to fabricate $\mathrm{Al}$ composites [12]. Friction stir processing has been demonstrated in creating Local Metal Matrix Composites (LMMCs) in light alloys matrix. The LMMCs are produced contextually to the weld using friction stir welding. The results have revealed an

*Corresponding author: tel.: +91 9876613657; e-mail address: skmangal_pec@rediffmail.com 
increase in the maximum load capacity under shear test concerning the reference conditions [13]. Multilayer MMCs were prepared by the hot rolling process of matrix foils. These composites were found compact and sound with good strength and modulus of elasticity but have low ductility [14]. Some of the lowcost MMC fabrication techniques developed in the past few decades include stir casting, squeeze casting, compo-casting and continuous casting. However, the stir casting technique is the most commonly used process by industries and accounts for one of the most extensive primary production of the MMCs [8]. The properties of the fabricated composite by stir casting process are mainly dependent on its process parameters such as furnace temperature, stirring speed, stirring time, holding and solidification behaviour [15]. The assistance of ultrasonic vibrations in stir casting is a prominent feature that enhances the properties of the fabricated MMCs. This was found an amenable process for medium to large-scale production [16]. The presence of an inert environment also plays a significant role in the improvement of the properties of the fabricated MMCs by preventing losses in its molten material when compared to conventional stir casting technique. An inert environment inside the furnace can be created by supplying inert gases gas like helium, argon, etc. $[17,18]$. Besides the fabrication techniques, the reinforcement type plays another important role to achieve the desired physical and microstructural properties of the composites. In standard MMCs, ceramics like alumina, silicon carbide, silicon nitride, boron, boron nitride, boron carbide, titanium carbide, etc. are being used extensively as reinforcement particulates [19-23]. Different metal oxides can also be injected in the molten matrix melt to produce in-situ matrix composites. The chemical reaction between these oxides produced nanoparticles which acted as the reinforcing agent [24]. Different salts can also be used in in-situ MMCs fabrication for the formation and growth of reinforcements in the matrix melt. The chemical reactions of these salts with matrix melt have resulted in the production of reinforcement particulates [25]. Although the addition of these reinforcement particles to matrix enhances some of its mechanical properties, their poor wetting property generally results in weak interfacial bonding and tends to form voids. It also leads to the agglomeration of these particles and forms clusters. This property adversely affects the corrosion behaviour \& ductility of the cast MMCs [23, 26]. The load transfer efficiency of the soft matrix decreases after reinforcement of the hard ceramic particles which reduces the strength of the MMCs [23, 26-28]. The size of the reinforced particulates also affects the overall properties of the MMCs. Large size reinforced particles generally reduce the fatigue life of the fabricated composite [29]. Thus, a major problem associ- ated with liquid metallurgy manufacturing route is the non-uniform distribution of the particulate mainly due to its poor wettability and gravity regulated segregation.

Available literature revealed that no casting process had been explored in which the vacuum was created in the mould during the pouring of the molten material. This may play a significant role in enhancing the mechanical properties of the fabricated MMC and its microstructure. Keeping in view the above facts, a newly developed gas injection bottom pouring vacuum stir casting technique has been envisaged for fabrication of the MMCs which is fully automated and one of its kind. Different tests have been conducted on the fabricated Al-MMC samples to investigate their physical and mechanical properties. The presence of elements, grain morphology and microstructure in the fabricated composites are investigated by using Scanning Electron Microscope (SEM) and Energy Dispersive X-ray Spectroscopy (EDS) techniques. From the characterization of the MMCs, it is concluded that the envisaged method fabricated homogeneously reinforced MMCs with excellent engineering properties.

\section{Gas injection bottom pouring vacuum stir casting process}

Stir casting process is considered as a low-cost manufacturing technique to fabricate MMCs. However, this method of fabrication consists of many steps viz. separate pre-heating of reinforcement particles, manual stirring, separate pre-heating of mould, manual pouring, etc. which induces various defects in the fabricated MMCs. With an objective to minimize these casting defects, a new gas injection bottom pouring vacuum stir casting process is proposed for the fabrication of the $\mathrm{Al} / \mathrm{Al}_{2} \mathrm{O}_{3} \mathrm{MMC}$. Figure 1 (a) shows a schematic representation of the process setup, its various components as well as its inside mechanism. Figure 1(b) shows the actual image of the setup, and in the insets, the mould and the fabricated Al-MMC are shown. The casting setup mainly consists of the following components:

- induction resistance furnace having temperature regulation system and display indicator,

- two reinforcement particulate chambers,

- automatic stirring mechanism with steel impeller,

- vacuum chamber,

- mould pre-heater,

- temperature sensors,

- inert gas supply system.

The setup consists of an induction resistance furnace having a temperature regulation system and display indicator. The furnace has a capacity of $1500^{\circ} \mathrm{C}$ with an accuracy of $\pm 2{ }^{\circ} \mathrm{C}$ and temperature regulator 


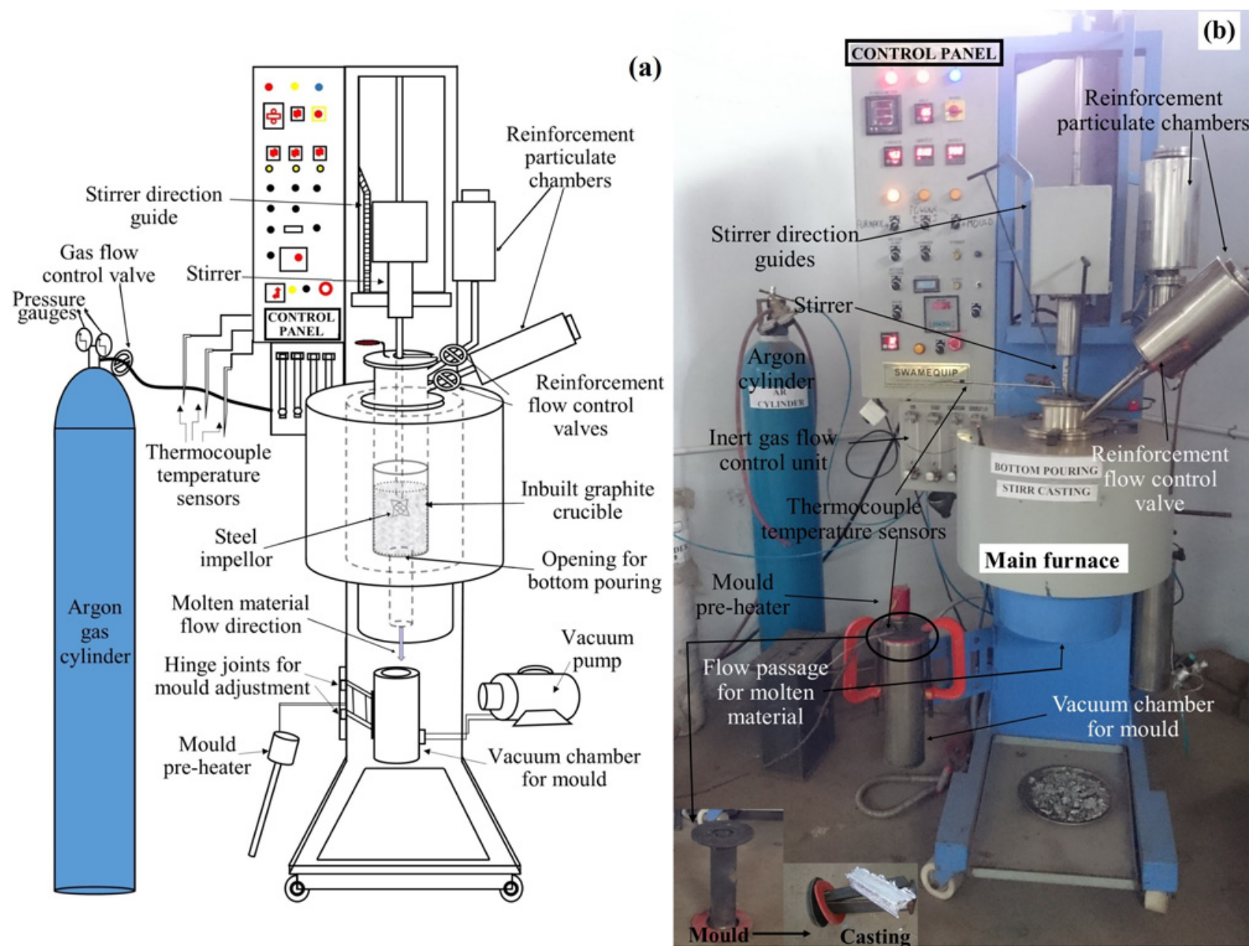

Fig. 1. (a) Schematic diagram of gas injection bottom pouring vacuum stir casting setup and (b) actual image of casting setup used for fabrication of $\mathrm{Al} /\left(\mathrm{Al}_{2} \mathrm{O}_{3}\right)$-MMC inset showing the mould used for along with the fabricated casting.

cum digital recorder to maintain proper temperature inside the furnace. Matrix is melted in a graphite crucible which is fixed inside the furnace. The crucible has a bottom opening for pouring purpose which is controlled by a switch provided on the control panel.

The setup consists of two reinforcement particulate chambers which facilitate the fabrication of hybrid MMCs having more than one reinforcement. These reinforcement particulate chambers are installed with induction heating mechanism (heating capacity $800^{\circ} \mathrm{C}$ with an accuracy of $\pm 2{ }^{\circ} \mathrm{C}$ ) for preheating of particles to remove its moisture, hydroxides and other gases. These chambers are connected to the matrix melting furnace with a tube having a valve mechanism to control the flow rate of the reinforcements. The setup facilitates both melting of the metal matrix and preheating of the hard reinforcement particulates simultaneously during casting of the composites.

The molten matrix and the reinforcement particulates are mixed by steel impeller through an automatic steering mechanism. The stirrer has a speed regulator and tachometer to control the stirring speed. It has an automatic downward and upward movement con- troller. The automatic stirring mechanism plays an important role in the homogenized distribution of the hard reinforcement particles in the matrix by agitating the mixture intensely during the stirring process.

The vacuum chamber of the setup is used to create the desired vacuum in the mould with the help of a vacuum pump. The mould is specially designed to fit in the chamber as it requires a proper adjustment for creating the desired vacuum. The vacuum is created before pouring of the molten material. A heating arrangement for baking and pre-heating of the mould is also provided in the setup to heat it up to $400^{\circ} \mathrm{C}$.

Three temperature sensors are used to measure the temperatures of the furnace, the particulate chambers and the mould simultaneously. These sensors are movable and can be placed where-ever required. The setup has an inert gas supply system which removes oxygen from the furnace resulting in an oxygen-free surrounding, which is very much necessary to prevent the molten matrix oxidation. This system can also be utilized for those castings which are very sensitive under an oxidized condition in their molten state (e.g. magnesium). 
Table 1. The composition of aluminium AA6063 T6 alloy (wt.\%)

\begin{tabular}{cccccccccc}
\hline $\mathrm{Si}$ & $\mathrm{Fe}$ & $\mathrm{Cu}$ & $\mathrm{Mn}$ & $\mathrm{Cr}$ & $\mathrm{Mg}$ & $\mathrm{Zn}$ & $\mathrm{Ti}$ & $\mathrm{Al}$ \\
\hline $0.2-0.6$ & 0.35 & 0.1 & 0.1 & 0.1 & $0.45-0.9$ & 0.1 & 0.1 & 97.5 \\
\hline
\end{tabular}

Table 2. Properties of aluminium 6063 T6 alloy

\begin{tabular}{cll}
\hline Sl. No. & Properties & Values \\
\hline 1. & Density & $2.7 \mathrm{~g} / \mathrm{cc}$ \\
2. & Melting point & $660^{\circ} \mathrm{C}$ \\
3. & Young's modulus (max.) & $68.3 \mathrm{GPa}$ \\
4. & Elongation & $10 \%$ \\
5. & Max. tensile strength & $180 \mathrm{MPa}$ \\
6. & Yield strength & $160 \mathrm{MPa}$ \\
\hline
\end{tabular}

Ta ble 3. Properties of alumina $\left(\mathrm{Al}_{2} \mathrm{O}_{3}\right)$

\begin{tabular}{cll}
\hline Sl. No. & Properties & \\
\hline 1. & Chemical formula & $\mathrm{Al}_{2} \mathrm{O}_{3}$ \\
2. & Density & $3.95 \mathrm{~g} / \mathrm{cc}^{-1}$ \\
3. & Molar mass & $101.96 \mathrm{~g} \mathrm{~mol}$ \\
4. & Melting point & $2072^{\circ} \mathrm{C}$ \\
5. & Shear strength & $330 \mathrm{MPa}$ \\
\hline
\end{tabular}

Table 4. Comparison of properties of experimental with theoretical aluminium $6063 \mathrm{~T} 6$ alloy

\begin{tabular}{clll}
\hline Sl. No. & Properties & Theoretical & Experimental \\
\hline 1. & Density & $2.7 \mathrm{~g} / \mathrm{cc}$ & $2.59 \mathrm{~g} / \mathrm{cc}$ \\
2. & Melting point & $660^{\circ} \mathrm{C}$ & $657^{\circ} \mathrm{C}$ \\
3. & Elongation & $10 \%$ & $8.2 \%$ \\
4. & Maximum tensile strength & $180 \mathrm{MPa}$ & $172 \mathrm{MPa}$ \\
5. & Yield strength & $160 \mathrm{MPa}$ & $148 \mathrm{MPa}$ \\
\hline
\end{tabular}

\section{3. $\mathrm{Al} / \mathrm{Al}_{2} \mathrm{O}_{3} \mathrm{MMC}$ fabrication}

In the present work, aluminium alloy, AA6063 T6 (its composition is shown in Table 1) is used as the base material, i.e. matrix phase. Alumina $\left(\mathrm{Al}_{2} \mathrm{O}_{3}\right)$ is used as ceramic reinforcement phase with a maximum particle size $\leq 10 \mu \mathrm{m}$. The properties of the AA6063 aluminium alloy are shown in Table 2 while Table 3 shows the properties of reinforced alumina $\left(\mathrm{Al}_{2} \mathrm{O}_{3}\right)$ particulates. Composite samples were prepared by varying the alumina from 6 to $14 \%$ by weight in a step of $2 \%$. A sample without reinforcement was also cast and characterized for confirming its theoretical available properties. Table 4 shows the comparison of the experimental properties with the theoretical ones. The table proves a close agreement of the experimental results with the theoretical values. Figure $2 \mathrm{a}$ shows the SEM image of the cast AA6063 alloy with- out reinforcement while Fig. 2b shows its mapping. As green colour has been assigned to aluminium, it is clear from Fig. $2 \mathrm{~b}$ that the major component of the AA6063 alloy is the aluminium.

The aluminium alloy, AA6063, is first preheated to a temperature of $500^{\circ} \mathrm{C}$ for $2 \mathrm{~h}$. The graphite crucible of the furnace, the stirrer impeller and the mould is coated with zirconia paste and is baked for 3 to $4 \mathrm{~h}$. This is carried out at least one day before the casting. This process makes the setup components nonsticky with the molten material. Preheating of hard reinforced particulate is essential before adding to the molten matrix. The hard reinforced particulate alumina $\left(\mathrm{Al}_{2} \mathrm{O}_{3}\right)$ is preheated in the particulate reinforcement chamber at $650^{\circ} \mathrm{C}$ for $2 \mathrm{~h}$ to remove its moisture, hydroxides and other gases to improve its wettability with the Al matrix. The melting temperature of aluminium is observed to be $657^{\circ} \mathrm{C}$. The tempe- 

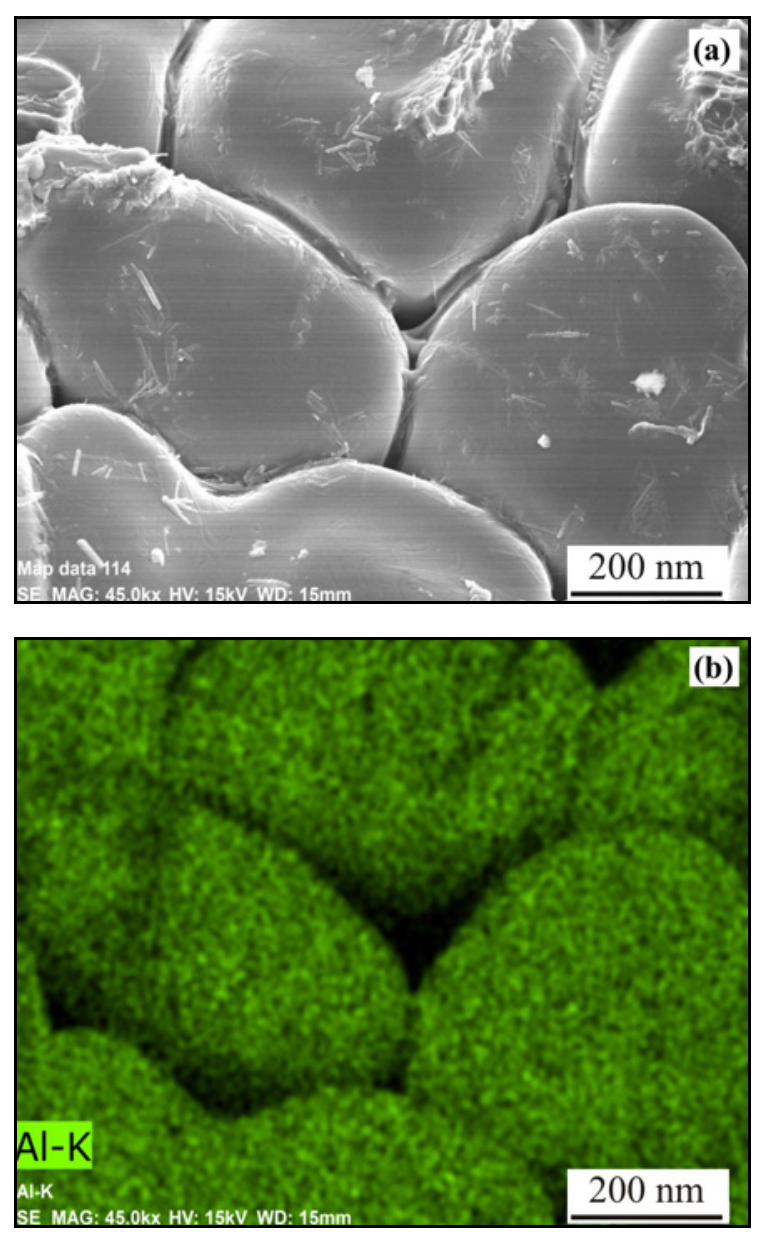

Fig. 2. (a) SEM image of cast AA6063 aluminium alloy without reinforcement and (b) mapping of the SEM image showing aluminium as its major element in the casting.

rature of the furnace is then increased beyond the liquidus temperature of the aluminium $\left(710^{\circ} \mathrm{C}\right)$ and maintained there for $30 \mathrm{~min}$ for complete melting of the matrix. The furnace temperature is now lowered $\left(\right.$ at $630^{\circ} \mathrm{C}$ ) below the liquidus temperature of the aluminium so that the slurry be converted into a semisolid state. At this point, the pre-heated $\mathrm{Al}_{2} \mathrm{O}_{3}$ particulate is added slowly and stirred with the zirconia coated steel impeller. The stirring is carried out at $350 \mathrm{rpm}$ for $10 \mathrm{~min}$ to ensure uniform scattering of the alumina particles in the aluminium alloy matrix. The slurry is heated above its melting temperature to get an entirely liquid state and again stirred thoroughly. The stirring process is repeated thrice which results in a more homogeneous distribution of alumina particulate and better microstructure when compared with the conventional casting process. The effect of the multi-step mixing process is the breakage of the interfacial gas layer which is present around the particle surfaces. It happens because of the abrasive action of the stirring which otherwise hinders wetting between

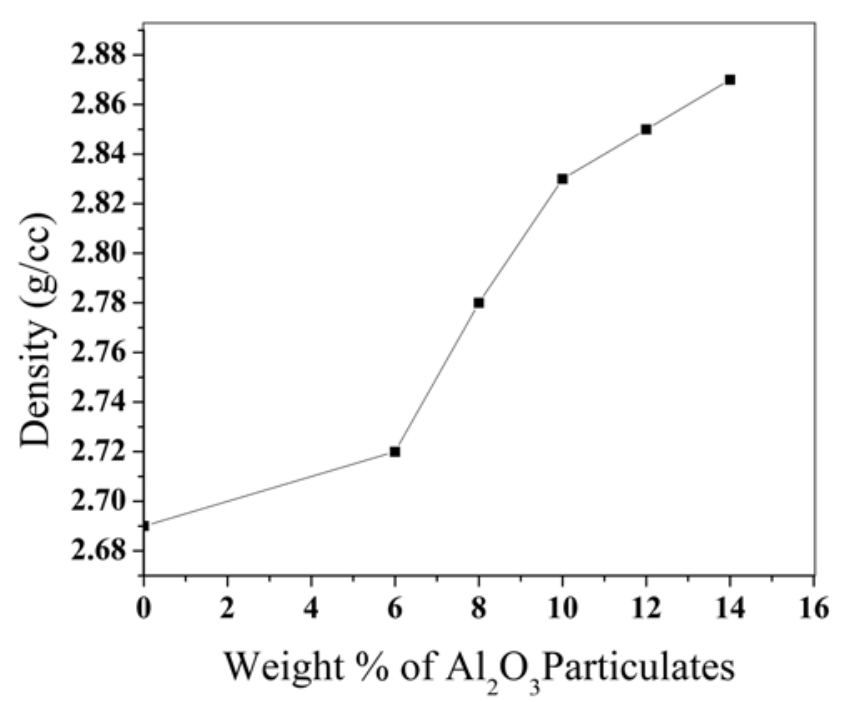

Fig. 3. Variation in density concerning percentage weight of $\mathrm{Al}_{2} \mathrm{O}_{3} \mathrm{p}$ in the fabricated MMCs.

the reinforcement particles and molten metal. The furnace temperature is now increased to $670^{\circ} \mathrm{C}$ during the pouring to increase the fluidity of the slurry. Besides the above, $1.0 \%$ magnesium by weight is also added to enhance the wettability of reinforcement particles.

\section{Results and discussion}

The bottom pouring vacuum stir casting setup is used for the fabrication of Al-MMC samples. Rectangular cross-section bars of Al-MMCs were cast with a different weight percentage of the alumina. Various experimental investigations are carried out on these samples to study the distribution of alumina reinforced particulates and mechanical properties. These are described below in detail.

\subsection{The density of fabricated $\mathrm{Al} / \mathrm{Al}_{2} \mathrm{O}_{3} p$ MMCs}

The density of the fabricated $\mathrm{Al} / \mathrm{Al}_{2} \mathrm{O}_{3}-\mathrm{MMC}$ samples is determined using Archimedes's principle. To measure it, a cuboidal piece sample of size $6 \mathrm{~cm} \times 3 \mathrm{~cm} \times 3 \mathrm{~cm}$ was used. The density of the fabricated Al-MMC samples $\left(\rho_{\mathrm{s}}\right)$ is then determined by utilizing the following relation:

$$
\rho_{\mathrm{s}}=\frac{w_{\mathrm{a}}\left(\rho_{\mathrm{w}}\right)}{w_{\mathrm{a}}-w_{\mathrm{w}}}
$$

where $\rho_{\mathrm{w}}$ is the density of water, $w_{\mathrm{a}}$ is the weight of the sample in air, $w_{\mathrm{w}}$ is the weight of the sample in water. Figure 3 shows the density variation of $\mathrm{Al}-\mathrm{MMCs}$ concerning the weight percentage of $\mathrm{Al}_{2} \mathrm{O}_{3} \mathrm{p}$ reinforcement. From this figure, it can be stated that 

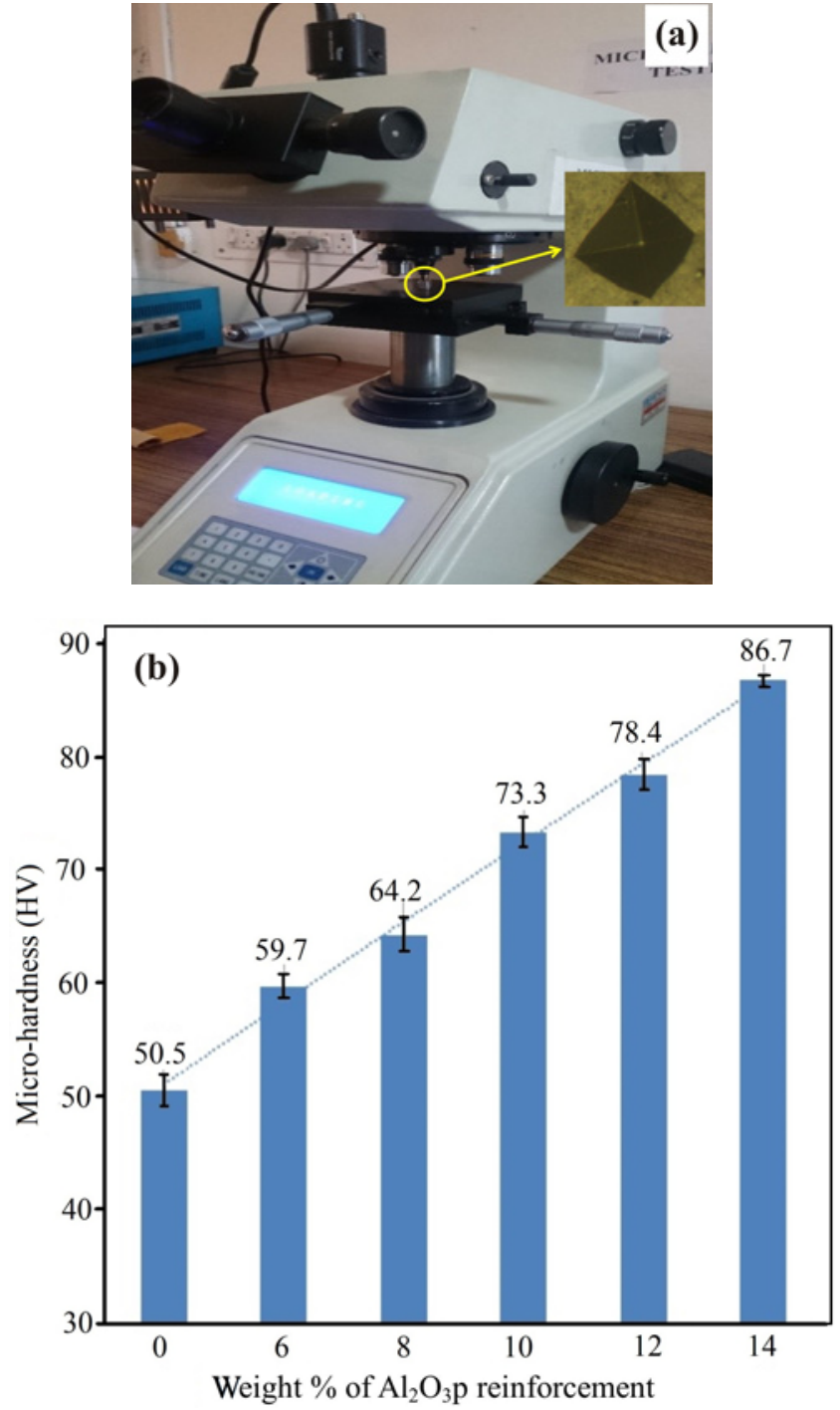

Fig. 4. (a) Microhardness tester HUAY IN HV-1000B and inset shows indentation mark at 500 magnification and (b) error bar graphs showing the repeatability of experiments for microhardness.

the mass density of the composite increases with an increase in the percentage of $\mathrm{Al}_{2} \mathrm{O}_{3}$ p. The density of $\mathrm{Al} /\left(6 \% \mathrm{Al}_{2} \mathrm{O}_{3}\right)$-MMC sample is found to be $4 \%$ higher than that of the cast Al-matrix, and it goes up by $11 \%$ for $\mathrm{Al} /\left(14 \% \mathrm{Al}_{2} \mathrm{O}_{3}\right)$-MMC sample. Hence, $\mathrm{Al}_{2} \mathrm{O}_{3}$ ceramic reinforcement has affected the density of fabricated MMC. It is due to uniform distribution of $\mathrm{Al}_{2} \mathrm{O}_{3}$ particulates in the $\mathrm{Al}$ matrix which was achieved by multi-step stirring of the proposed casting process. Besides the above factor, suction created in the vacuum chamber and higher density of $\mathrm{Al}_{2} \mathrm{O}_{3}$ particles has also resulted in the higher density of the cast MMC.

\subsection{Microhardness investigation}

Hardness is the property of a material that enables it to resist localized plastic deformation induced by either mechanical indentation or abrasion. It is considered to be a function of the stress required to produce some specific types of surface deformation. Hardness is an important parameter for the composites materials. The fabricated MMC samples are investigated for Vickers microhardness as the microhardness data for a specific material provide information regarding its wear, polishability and abrasive effect on the antagonist. For the hardness investigation, samples of desired sizes are machined and then polished to mirror finish level on a double disc polishing machine using different grades of emery papers (i.e. $600,800,1000$, 1200, 1500, and 2000 mesh), alumina polishing fluid and velvet cloth. For this testing, microhardness tester HUAY-IN HV-1000B is used (Fig. 4a). Inset of this figure shows the residual indentation on $\mathrm{Al} /(10 \%$ by weight of $\mathrm{Al}_{2} \mathrm{O}_{3} \mathrm{p}$ )-MMC sample after its testing at a magnification level of 500. During the test, a load of $200 \mathrm{~g}$ was applied with a dwelling time of $15 \mathrm{~s}$. The microhardness is determined by measuring the diagonals of the indentation. The hardness of each sample is measured five times for getting the precise and accurate results and also to eliminate the human \& other errors. Figure $4 \mathrm{~b}$ shows the error bar graph for the repeatability of the experimental data of microhardness for all the MMC samples. The height of the I-symbol shown above each bar represents the standard deviation for the corresponding MMC sample and the numeric value above each bar represents the corresponding mean microhardness value. The dotted line in Fig. 4b shows the trend for Vickers microhardness with different weight percentage of $\mathrm{Al}_{2} \mathrm{O}_{3}$ p. From Fig. 4b, it can be stated that the hardness shows an increasing trend with an increase in the weight percentage of alumina. The hardness was found to vary from $50.5 \mathrm{HV}$ (at $0.0 \%$ by weight of $\mathrm{Al}_{2} \mathrm{O}_{3} \mathrm{p}$ ) to $86.7 \mathrm{HV}$ (at $14 \%$ by weight of $\mathrm{Al}_{2} \mathrm{O}_{3} \mathrm{p}$ ) thus increasing by $71 \%$. The increase in the hardness with an increase in the weight $\%$ of $\mathrm{Al}_{2} \mathrm{O}_{3}$ p reinforcement is attributed to the hardness of the particulates which act as a barrier to the dislocations within the matrix. The presence of reinforcement particulates in the melt provides additional surface or layer for the solidification of the construct, thereby increasing the nucleation rate and decreasing the grain size.

\subsection{Maximum tensile strength investigation}

The effect of weight percentage of $\mathrm{Al}_{2} \mathrm{O}_{3} \mathrm{p}$ in Al-MMC on maximum tensile strength is investigated. The test specimens are prepared as per ASTM-B-557M standard (Fig. 5a). The experiments are conducted on universal testing machine model UTE 40 from $\mathrm{M} \mathrm{s}^{-1}$ Fuel Instruments and Engineers Pvt. Ltd. Figures 5b,c show the prepared samples for the tensile strength testing and fractured sam- 

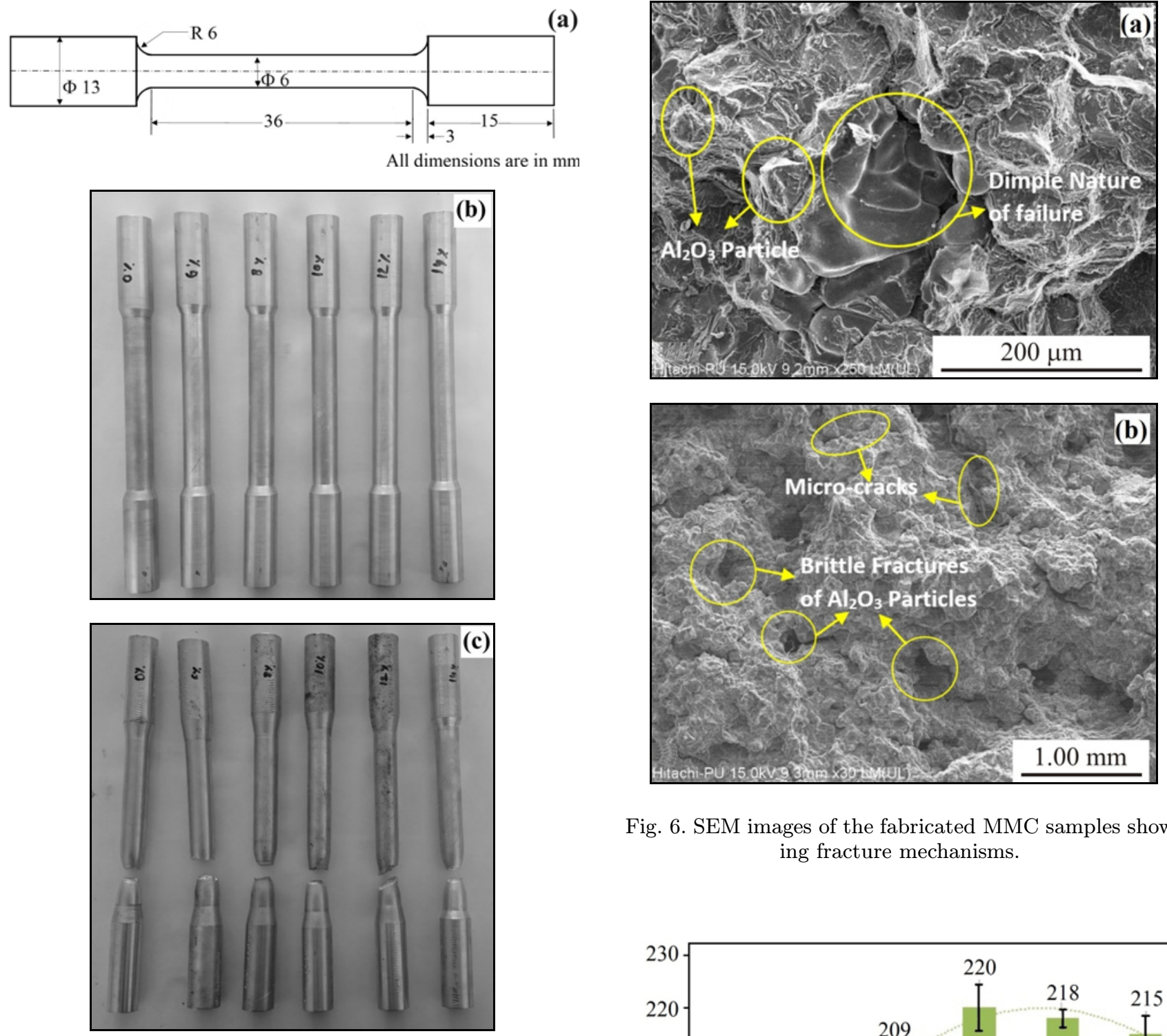

Fig. 6. SEM images of the fabricated MMC samples showing fracture mechanisms.

Fig. 5. (a) Geometry of the tensile test specimen as per the ASTM-B-557-M standards, (b) tensile test specimens of cast $\mathrm{Al} / \mathrm{Al}_{2} \mathrm{O}_{3}$ p-MMC samples having a different weight \% of $\mathrm{Al}_{2} \mathrm{O}_{3} \mathrm{p}$ reinforcement, and (c) the fractured specimens after tensile testing.

ples after testing, respectively. The maximum tensile strength of each component of the MMC was tested three times to ensure precise, accurate results and also to eliminate the human \& other errors. It has been found from this investigation that the maximum tensile strength of the fabricated MMC increases and ductility decreases substantially with an increase in the weight percentage of $\mathrm{Al}_{2} \mathrm{O}_{3} \mathrm{p}$ reinforcement. This increase in the maximum tensile strength is due to the increase in the hardness of the fabricated MMCs which is caused by the presence of $\mathrm{Al}_{2} \mathrm{O}_{3} \mathrm{p}$ in the matrix. These particles provide more strength to the matrix by offering more re-

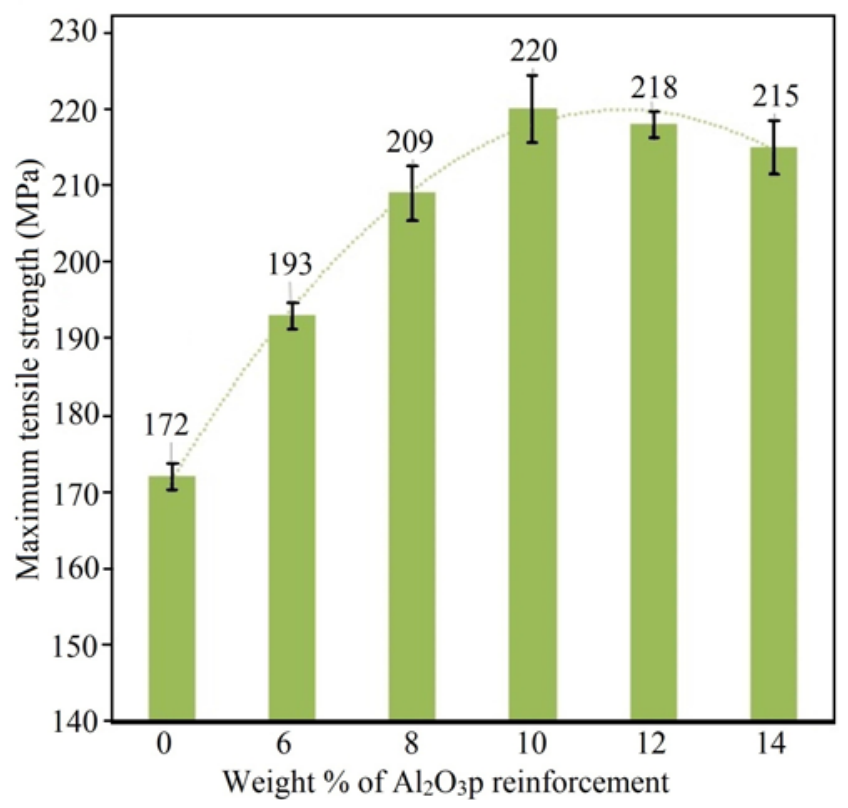

Fig. 7. Error bar graph showing the repeatability of experiments for maximum tensile strength testing. 

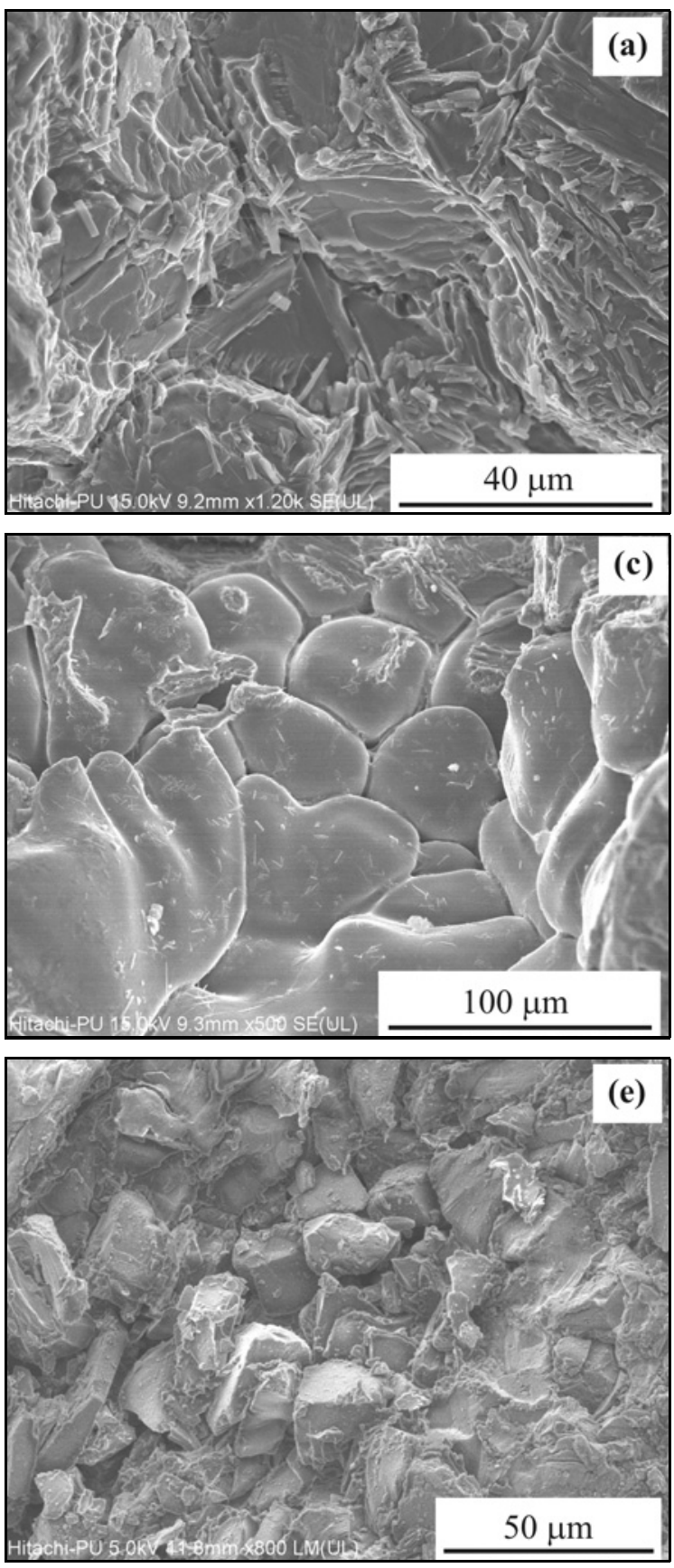
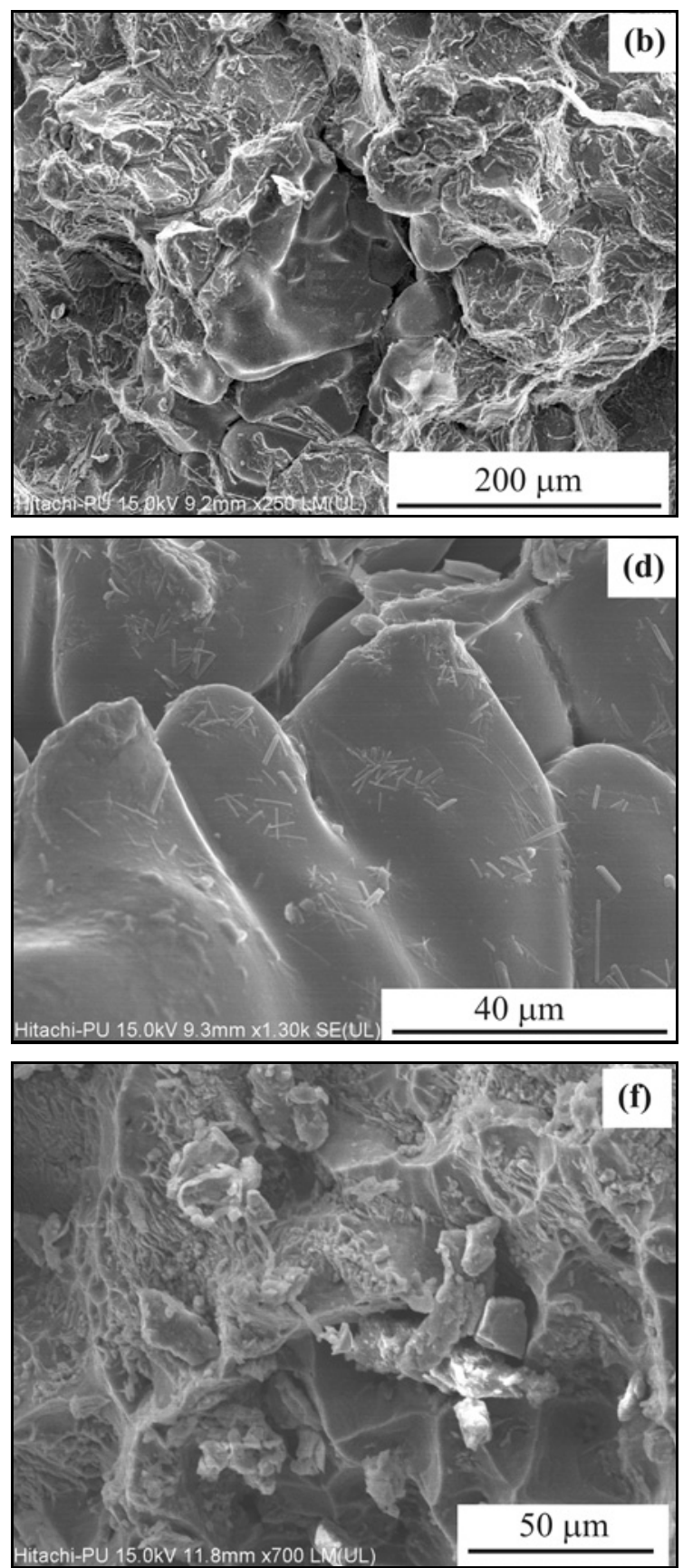

Fig. 8. SEM images of fabricated $\mathrm{Al} /\left(10 \%\right.$ by weight of $\left.\mathrm{Al}_{2} \mathrm{O}_{3} \mathrm{p}\right)-\mathrm{MMC}$ sample at different magnifications; (a) at $40 \mu \mathrm{m}$, $\times 1200$ magnification; (b) at $200 \mu \mathrm{m}, \times 250$ magnification; (c) at $100 \mu \mathrm{m}, \times 500$ magnification; (d) at $40 \mu \mathrm{m}, \times 1300$ magnification; (e) $\mathrm{Al} /\left(14 \%\right.$ by weight of $\left.\mathrm{Al}_{2} \mathrm{O}_{3} \mathrm{p}\right)$ at $50 \mu \mathrm{m}, \times 800$ magnification; (f) $\mathrm{Al} /\left(12 \%\right.$ by weight of $\left.\mathrm{Al}_{2} \mathrm{O}_{3} \mathrm{p}\right)$ at $50 \mu \mathrm{m}, \times 700$ magnification.

sistance to the tensile stress but also prone to localized crack initiation and increased effect of brittleness due to the formation of the local stress concentration site at the matrix-reinforcement interface. The maximum tensile strength of the cast $\mathrm{Al} /(10 \%$ by weight of $\mathrm{Al}_{2} \mathrm{O}_{3} \mathrm{p}$ )-MMC sample is found to be $220 \mathrm{MPa}$ (at the maximum load of $22 \mathrm{kN}$ with the corresponding displacement of $10.8 \mathrm{~mm}$ ). This is the maximum tensile strength found among all the fabricated MMC sam- ples which is $27 \%$ higher than the cast aluminium alloy 6063 .

The maximum tensile strength of the fabricated MMCs was found to have a decreasing trend after increasing the weight $\%$ of $\mathrm{Al}_{2} \mathrm{O}_{3} \mathrm{p}$ beyond $10 \%$. For example, the maximum tensile strength of the fabricated $\mathrm{Al} /\left(14 \%\right.$ by weight of $\left.\mathrm{Al}_{2} \mathrm{O}_{3} \mathrm{p}\right)$-MMC sample is $215 \mathrm{MPa}$ which is lesser by $5 \mathrm{MPa}$ as compared to the highest obtained value of maximum tensile strength 
among all the cast MMC samples. This is due to the reason that cast sample is becoming more brittle beyond the $10 \%$ by weight of reinforced $\mathrm{Al}_{2} \mathrm{O}_{3}$ p. Figure 6 shows the SEM images of the fractured specimen of $\mathrm{Al} /\left(10 \%\right.$ by weight of $\left.\mathrm{Al}_{2} \mathrm{O}_{3} \mathrm{p}\right)$-MMC sample. Analysis of the fractured surface of the MMC sample by SEM reveals that the cracked $\mathrm{Al}_{2} \mathrm{O}_{3}$ particles have ductile tear ridges which indicates both brittle and ductile fracture mechanism. This is due to a decrease in the ductility of the matrix when the $\mathrm{Al}_{2} \mathrm{O}_{3}$ p reinforced in it. Figure 7 shows the error bar graph for the repeatability of experimental data of maximum tensile strength for all the MMC samples. The height of the I-symbol above each bar represents the standard deviation for the corresponding MMC sample and the numeric value above each bar corresponds to respective mean maximum tensile strength. The dotted line in Fig. 7 shows the trend for maximum tensile strength varying with the weight percentage of $\mathrm{Al}_{2} \mathrm{O}_{3}$ p.

\subsection{Microstructure analysis}

In this research work, a multi-step stirring is used to ensure the uniform distribution of the reinforcement $\left(\mathrm{Al}_{2} \mathrm{O}_{3} \mathrm{p}\right)$ in the aluminium matrix and also to increase wettability. An adequate melt circulation is a must to break down the aggregation of bulk cohesive $\mathrm{Al}_{2} \mathrm{O}_{3}$ p to achieve better wettability and particulate distribution, for which multi-step mixing has played a crucial role. Figure 8 shows SEM images illustrating the microstructure of different fabricated MMC samples. Figures 8a,b show the dispersion of $\mathrm{Al}_{2} \mathrm{O}_{3} \mathrm{p}$ in MMC. It is clear from these figures that reinforcement particulate distribution is homogeneous in the fabricated composite samples. Figures $8 \mathrm{c}$, d show the microstructural characteristics and grain morphology of $\mathrm{Al} /\left(10 \%\right.$ by weight of $\left.\mathrm{Al}_{2} \mathrm{O}_{3} \mathrm{p}\right)$-MMC sample. The analysis of grain boundaries from these figures clearly shows equiaxed type of grains exists in the fabricated MMC samples. Figures 8e,f show the SEM image of $\mathrm{Al} /\left(14 \%\right.$ by weight of $\left.\mathrm{Al}_{2} \mathrm{O}_{3} \mathrm{p}\right)$ and $\mathrm{Al} /(12 \%$ by weight of $\left.\mathrm{Al}_{2} \mathrm{O}_{3} \mathrm{p}\right)$-MMC samples, respectively. These figures clearly show a higher concentration of $\mathrm{Al}_{2} \mathrm{O}_{3} \mathrm{p}$ reinforcement in the aluminium matrix which has induced an unwanted brittleness to the MMC samples hence reducing its ductility. This, in turn, has affected the maximum tensile strength of MMC samples.

\subsection{EDS of $\mathrm{Al} / \mathrm{Al}_{2} \mathrm{O}_{3} \mathrm{p} M M C s$}

Energy dispersive spectroscopy (EDS) is used for analysing the elements present in the fabricated $\mathrm{Al} / \mathrm{Al}_{2} \mathrm{O}_{3}-\mathrm{MMC}$ samples. The EDS has been conducted on all the fabricated MMC samples, and the results are presented in Fig. 9. In this figure, the $x$-axis represents $\mathrm{keV}$, and the $y$-axis represents $\mathrm{cps} / \mathrm{eV}$. From this figure, the presence of aluminium, carbon, oxygen, silicon, magnesium as its major elements with their weight percentage can be observed when all the elements are selected for the analysis in EDS testing. From the EDS spectra, it has also been observed that the weight $\%$ of the oxygen in the MMC samples increased with an increased weight $\%$ of $\mathrm{Al}_{2} \mathrm{O}_{3}$ p reinforcement. When the EDS testing is done for the elements as well as for their compounds, the presence of metal oxides, i.e. $\mathrm{Al}_{2} \mathrm{O}_{3}, \mathrm{MgO}$ and $\mathrm{SiO}_{2}$ are observed in the MMC samples which are shown in Fig. 9(e).

\subsection{Mapping of $\mathrm{Al} / \mathrm{Al}_{2} \mathrm{O}_{3}$ p $M M C$}

Mapping of the fabricated $\mathrm{Al} / \mathrm{Al}_{2} \mathrm{O}_{3}$-MMC samples has been carried out to find the distribution of the inspected elements after EDS testing. Different colours have been assigned to each element, and their mapping is shown in Fig. 10. Figure 10a shows the SEM image for which the mapping has been carried out. Figure $10 \mathrm{~b}$ shows the collective mapping of aluminium, oxygen, carbon and magnesium while Figs. 10c-f show the mapping of its individual element, i.e. aluminium, carbon, oxygen and magnesium, respectively. The intensity of the colours of each element depends upon the number of times the surface has been scanned. In Fig. 10b the surface is scanned only three times whereas in Figs. 10c-f, the surface scanning is done for ten times for each element.

\section{Conclusions}

In the present study, a gas injection bottom pouring vacuum stir casting process has been utilized for the fabrication of $\mathrm{Al}$ matrix based composites which is fully automated and one of its kind. The different weight fractions of $\mathrm{Al}_{2} \mathrm{O}_{3}$ reinforcement particulates are selected. Different tests and investigations are conducted on the cast Al-MMC samples for recognizing its various physical as well as mechanical properties. The SEM images of the fabricated composite samples have been undertaken for microstructural characterization and investigation of its grain morphology. Presence of various elements like $\mathrm{Al}, \mathrm{Mg}, \mathrm{C}, \mathrm{O}, \mathrm{Mn}, \mathrm{Fe}$, etc. and compounds like $\mathrm{Al}_{2} \mathrm{O}_{3}, \mathrm{SiO}_{2}$ and $\mathrm{MgO}$ has been detected through Energy dispersive spectroscopy (EDS) analysis. Mapping has also been made to find the respective positions of the present elements. Based on this research work, the following conclusions have been drawn:

1. The proposed gas injection bottom pouring vacuum stir casting process for MMC casting has produced sound composites. The supply of argon gas in the induction furnace is successful in controlling the inside atmosphere during the fabrication of these composites. 

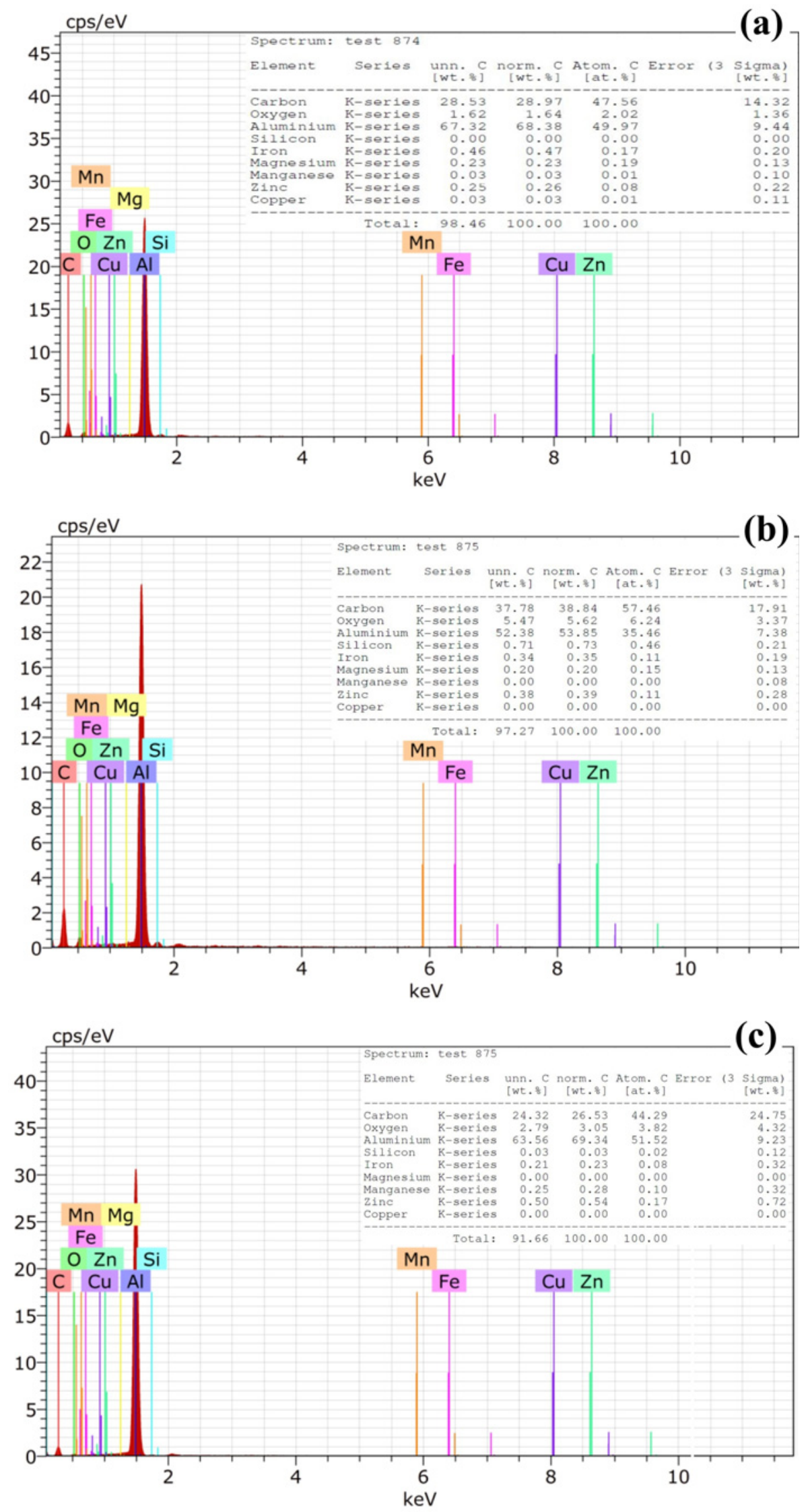

Fig. 9a,b,c. EDS spectra of (a) $\mathrm{Al} /\left(6 \%\right.$ by weight of $\mathrm{Al}_{2} \mathrm{O}_{3}$ p), (b) $\mathrm{Al} /\left(8 \%\right.$ by weight of $\mathrm{Al}_{2} \mathrm{O}_{3}$ p), (c) $\mathrm{Al} /(10 \%$ by weight $\mathrm{Al}_{2} \mathrm{O}_{3} \mathrm{p}$ ), MMC samples. 

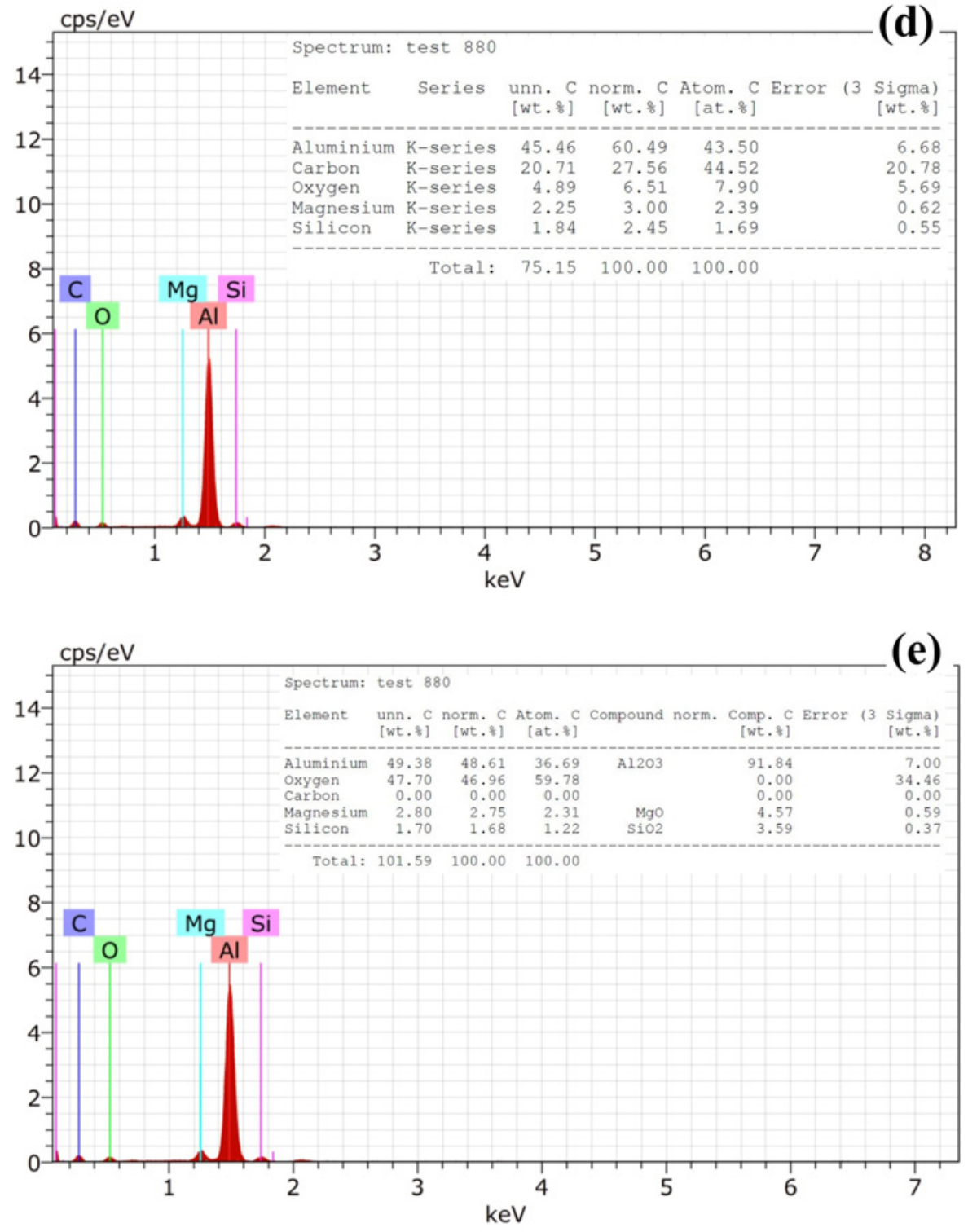

Fig. 9d,e. EDS spectra of (d) $\mathrm{Al} /\left(12 \%\right.$ by weight of $\left.\mathrm{Al}_{2} \mathrm{O}_{3} \mathrm{p}\right)$ and (e) $\mathrm{Al} /\left(14 \%\right.$ by weight of $\left.\mathrm{Al}_{2} \mathrm{O}_{3} \mathrm{p}\right) \mathrm{MMC}$ samples.

2. Multi-step stirring has played a significant role in the homogeneous distribution of $\mathrm{Al}_{2} \mathrm{O}_{3}$ p reinforcement by breaking the gas layer present around the particles surfaces which otherwise hinders wetting between the reinforcement particles and molten metal.

3. The fully automated process to pour the molten material from the bottom of the crucible and creation of a vacuum in the mould during the pouring eliminated the porosity like a defect and improved the morphology of the cast MMC.

4. The density of Al-MMC increased with an increase in the weight fraction of $\mathrm{Al}_{2} \mathrm{O}_{3}$ particulates. The composite was found to possess higher density in comparison to the aluminium matrix. The results conclude that the density of the fabricated MMC with $6 \%$ by weight of the $\mathrm{Al}_{2} \mathrm{O}_{3} \mathrm{p}$ is $4 \%$ higher than that of the pure Al-matrix. It further has gone up by $11 \%$ for a composite sample having $14 \%$ by weight of $\mathrm{Al}_{2} \mathrm{O}_{3} \mathrm{p}$ reinforcement.

5. The hardness of Al-MMC has an increasing trend with an increase in the weight percentage of hard reinforcement particles. The results reveal that the hardness of $\mathrm{Al} /\left(14 \%\right.$ by weight of $\left.\mathrm{Al}_{2} \mathrm{O}_{3}\right)-\mathrm{MMC}$ is $86.7 \mathrm{HV}$ which is $71 \%$ higher than the microhardness of Al-matrix.

6. Maximum tensile strength was initially found to have an increasing trend with an increase in weight fraction of reinforcement $\mathrm{Al}_{2} \mathrm{O}_{3} \mathrm{p}$ in the composite. Beyond $10 \%$ weight of $\mathrm{Al}_{2} \mathrm{O}_{3} \mathrm{p}$ reinforcement, the maximum tensile strength found a decreasing trend. Maximum tensile strength for $\mathrm{Al} /(10 \%$ by weight of $\mathrm{Al}_{2} \mathrm{O}_{3} \mathrm{p}$ )-MMC sample was determined as $220 \mathrm{MPa}$ at maximum load of $22 \mathrm{kN}$ and corresponding displacement of $10.8 \mathrm{~mm}$. This is $27 \%$ higher than the maxi- 

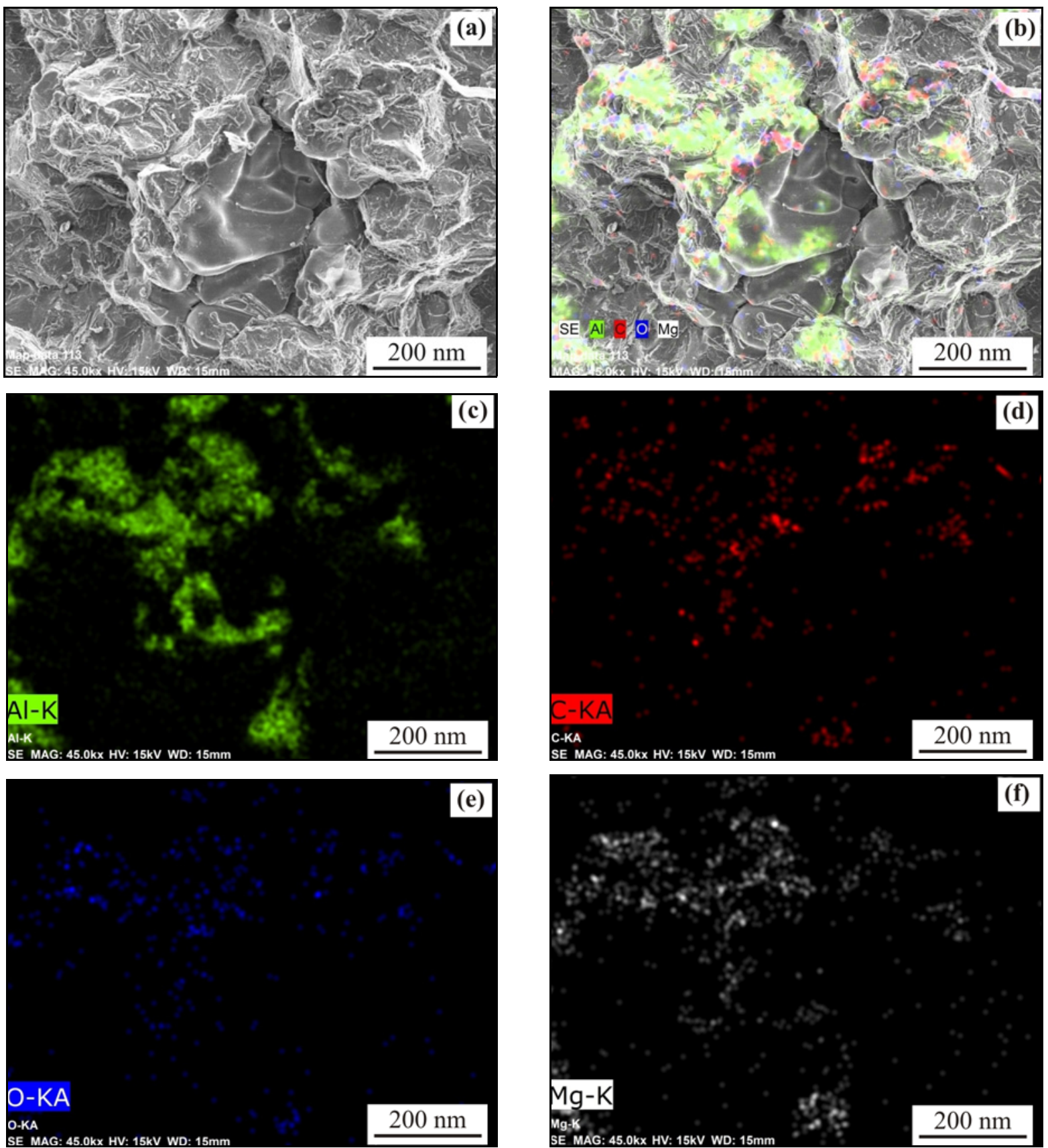

Fig. 10. Mapping of the fabricated $\mathrm{Al} / \mathrm{Al}_{2} \mathrm{O}_{3}-\mathrm{MMC}$ samples showing (a) SEM images for which the mapping has carried out, (b) distribution of $\mathrm{Al}, \mathrm{C}, \mathrm{O}$ and $\mathrm{Mg}$ elements, (c) distribution of $\mathrm{Al}$, (d) distribution of $\mathrm{C}$, (e) distribution of oxygen, and (f) distribution of $\mathrm{Mg}$.

mum tensile strength of Al-matrix.

This research work highlighted the successful application of the automated gas injection bottom pouring vacuum multi-stir casting process for the fabrication of sound MMC. The fabricated MMCs have a homogeneous distribution of reinforcement particulate, eliminated porosity and voids like defects with an improved morphology which has given higher density, hardness and tensile strength. The features and results obtained from the proposed MMC fabrication technique can be utilized for the fabrication of other types of MMCs for varied and different engineering applications.

\section{Acknowledgements}

The authors acknowledge Production \& Industrial Engineering Department; Materials \& Metallurgical Engineering Department, Punjab Engineering College, Chandigarh and Sophisticated Analytical Instrumentation Facil- 
ity, Panjab University, Chandigarh with thanks for providing their laboratory support for this research work.

\section{References}

[1] Smith, W.F., Hashemi, J., Prakash, R.: Materials Science and Engineering. India, Tata McGraw Hill Education Private Ltd., 2014.

[2] Clyne, T. W., Withers, P. J.: An Introduction to Metal Matrix Composites. Cambridge University Press, 1993. doi:10.1017/CBO9780511623080

[3] Lloyd, D. J.: Int. Mater. Reviews, 39, 1994, p. 1. https://doi:10.1179/imr.1994.39.1.1

[4] Babu, N. H., Tzamtzis, S., Barekar, N., Patel, J. B., Fan, Z.: Solid State Phenomena, 141-143, 2008, p. 373. doi:10.4028/www.scientific.net/SSP.141-143.373

[5] Rawal, S.: JOM, 53, 2001, p. 14. doi:10.1007/s11837-001-0139-z

[6] Chawla, N., Chawla, K. K.: JOM, 58, 2006, p. 67. https://doi:10.1007/s11837-006-0231-5

[7] Bushlya, V., Lenrick, F., Gutnichenko, O., Petrusha, I., Osipov, O., Kristiansson, S., Stahl, J. E.: Wear, 376-377, 2017, p. 152. doi:10.1016/j.wear.2017.01.036

[7] Fan, Z., Tsakiropoulos, P., Miodownik, A. P.: J. Mater. Sci., 29, 1994, p. 141. doi:10.1007/BF00356585

[9] Surappa, M. K.: Sadhana, 28, 2003, p. 319. doi:10.1007/BF02717141

[10] Rojas, J. I., Siva, V. B., Sahoo, K. L., Crespo, D.: Journal of Alloys and Compounds, 744, 2018, p. 445. doi:10.1016/j.jallcom.2018.02.103

[11] Reddy, M. P., Himyan, M. A., Ubaid, F., Shakoor, R. A., Vyasaraj, M., Gurura, P., Yusuf, M., Mohamed, A. M. A., Gupta, M.: Ceramics International, 44, 2018, p. 9247. doi:10.1016/j.ceramint.2018.02.135

[12] Hu, Z., Chen, F., Xu, J., Nian, Q., Lin, D., Chen, C., Zhu, X., Chen, Y., Zhang, M.: Journal of Alloys and Compounds, 746, 2018, p. 269. doi:10.1016/j.jallcom.2018.02.272

[13] Buffa, G., Campanella, D., Fratini, L.: Journal of Manufacturing Processes, 28, 2017, p. 422. doi:10.1016/j.jmapro.2017.04.008

[14] Jovanović, M. T., Lić, N., Cvijović-Alagić, I., Maksimović, V., Zec, S.: Transactions of Nonferrous Metals Society of China, 27, 2017, p. 1907. doi:10.1016/S1003-6326(17)60215-2
[15] Manna, A., Mahapatra, P. B., Bains, H. S.: J. Compos. Mater., 45, 2011, p. 2003. doi: $10.1177 / 0021998310394691$

[16] Pandey, U., Purohit, R., Agarwal, P., Dhakad, S. K., Rana, R. S.: Materials Today Proceedings D, 4, 2017, p. 5452. doi:10.1016/j.matpr.2017.05.057

[17] Hira, J., Mangal, S. K., Manna, A.: Arab J Sci Eng., 40, 2015, p. 2730. doi:10.1007/s13369-015-1755-1

[18] Bauri, R., Surappa, M. K.: Science and Technology of Advanced Materials, 8, 2007, p. 494. doi:10.1016/i.stam.2007.07.004

[19] Alizadeh, M., Paydar, M. H., Terada, D., Tsuji, N.: Mater. Sci. Eng. A, 540, 2012, p. 13. doi:10.1016/i.msea.2011.12.026

[20] Alizadeh, M., Paydar, M. H., Sharifian, J. F.: Compos. B, 44, 2013, p. 339 . doi:10.1016/j.compositesb.2012.04.069

[21] Alizadeh, M., Salahinejad, E.: J. Alloys Compd., 620, 2015, p. 180. doi:10.1016/j.jallcom.2014.08.249

[22] Yazdani, A., Salehinejad, E.: Mater. Des., 32, 2011, p. 3137. doi:10.1016/i.matdes.2011.02.063

[23] Khoram Khorshid, S., Alizadeh, M., Taghvaei, A. H., Scudino, S.: Materials \& Design., 2015, p. 137. doi:10.1016/j.matdes.2015.10.063

[24] Afkham, Y., Khosroshahi, R. A., Rahimpour, S., Aavani, C., Brabazon, D.: Archives of Civil and Mechanical Engineering, 18, 2018, p. 215. doi:10.1016/i.acme.2017.06.011

[25] Liu, X., Liu, Y., Huang, D., Han, Q., Wang, X.: Materials Science and Engineering A, 705, 2017, p. 55. doi:10.1016/j.msea.2017.08.047

[26] Yu, P., Kim, K. B., Das, J., Baier, F., Xu, W., Eckert, J.: Scr. Mater., 54, 2006, p. 1445. doi:10.1016/j.scriptamat.2006.01.001

[27] Wang, Z., Prashanth, K. G., Scudino, S., Chaubey, A. K., Sordelet, D. J., Zhang, W. W., Li, Y. Y., Eckert, J.: J. Alloys Compd., 586, 2014, p. 5419. doi:10.1016/j.jallcom.2013.04.190

[28] Cheng, S., Yang, G., Wang, J., Yang, C., Zhu, M., Zhu, Y.: J. Mater. Sci., 44, 2009, p. 3420. doi:10.1007/s10853-009-3454-3

[29] Pramanik, A., Basak, A. K.: Engineering Fracture Mechanics, 191, 2018, p. 33 doi:10.1016/j.engfracmech.2018.01.013 